\title{
Impactos ambientais no Parque Natural Municipal de Cabedelo - Estado do Paraíba (PB), Brasil
}

\author{
Environmental impacts in the Cabedelo Municipal Natural \\ Park - State of Paraíba, Brazil
}

\section{Impactos ambientales en el Parque Natural Municipal de Cabedelo - Estado de Paraíba, Brasil}

\author{
Wendel Pereira de Limal \\ Secretaria da Segurança e da Defesa Social da Paraíba, Brasil \\ Henrique Elias Pessoa-Gutierres ${ }^{2}$ \\ Universidade Federal da Paraíba - UFPB, Brasil
}

\begin{abstract}
Resumo
Para a Geografia, o estudo das Unidades de Conservação é fundamental para se compreender as relações entre sociedade-natureza. O presente trabalho tem o objetivo de analisar as atividades humanas e os impactos ambientais identificados no interior e no entorno do Parque Natural Municipal de Cabedelo, que abriga um importante patrimônio natural de restinga, encravada na área urbana do município de Cabedelo, estado Paraíba, na região Nordeste do Brasil. Por meio do método geossistêmico, os procedimentos metodológicos adotados consistiram na análise bibliográfica, pesquisa documental em órgãos públicos, trabalhos de campo para a execução de registros fotográficos, observações in loco e a aplicação de questionários junto às moradoras. O local tem sido alvo de diversas ações impactantes provenientes das atividades antropogênicas e da falta de gestão por parte
\end{abstract}

1 Bacharel em Geografia (UFPB). Secretaria da Segurança e da Defesa Social da Paraíba (SEDS). E-mail: wendel140800@hotmail.com (D) https://orcid.org/0000-0002-9428-8388

2 Doutor em Geografia pela Universidade Federal de Pernambuco. Geógrafo do Laboratório de Planejamento e Gestão Ambiental (LAPLAG), Departamento de Geociências da Universidade Federal da Paraíba - UFPB. Cidade Universitária, João Pessoa, Paraíba, Brasil, 58051-900. E-mail: hepg86@hotmail.com (D) https://orcid.org/0000-0003-0220-3410 
do poder público municipal, o que tem reforçado a percepção, por parte da população local, de que a situação do parque vem piorando.

Palavras-chave: Unidades de Conservação; Parque Natural Municipal de Cabedelo; área urbana; ações impactantes; atividades antropogênicas.

\begin{abstract}
In geography, the study of conservation units is essential for understanding the relationships between society and nature. The present work aims to analyze human activities and the environmental impacts identified in and around the Cabedelo Municipal Natural Park, which houses an important natural heritage of restingas, located in the urban area of the municipality of Cabedelo, state of Paraíba, in Northeastern Brazil. According to geosystemic methodology, the methodological procedures adopted consisted of bibliographic analysis, documentary research in public agencies, field work for the generation of photographic records, on-site observations and the application of questionnaires to residents. The site has been the target of several impactful actions arising from anthropogenic activities and the lack of adequate management by municipal authorities, which has reinforced the perception on the local population that the park's situation is worsening.
\end{abstract}

Keywords: Conservation units; Cabedelo Municipal Natural Park; Urban area; Impactful actions; Anthropogenic activities.

\title{
Resumen
}

Para la geografía, el estudio de las unidades de conservación es fundamental para comprender las relaciones entre la sociedad y la naturaleza. Este documento tiene como objetivo analizar las actividades humanas y los impactos ambientales identificados dentro y alrededor del Parque Natural Municipal de Cabedelo, que alberga un importante patrimonio natural de restinga, enclavado en el área urbana de Cabedelo, estado de Paraíba, Brasil. Región noreste de Brasil. A través del método geosistémico, los procedimientos metodológicos adoptados consistieron en análisis bibliográfico, investigación documental en agencias públicas, trabajo de campo para la ejecución de registros fotográficos, observaciones in situ y la aplicación de cuestionarios a los residentes. El sitio ha sido objeto de varias acciones impactantes como resultado de actividades antropogénicas y la falta de gestión por parte del gobierno municipal, lo que ha reforzado la percepción, por parte de la población local, de que la situación del parque ha empeorado.

Palabras clave: Unidad de Conservación; Parque Natural Municipal de Cabedelo; área urbana; acciones impactantes; actividades antropogénicas

\section{Introdução}

A notoriedade para as questões ambientais amplamente difundidas na atualidade tem no seu passado recente a explicação para tamanha importância e destaque. Como todo ramo técnico-científico, o desenvolvimento fez surgir uma série de conceitos, ora utilizados por outras áreas 
científicas, ora utilizados, exclusivamente, pelas ciências afins aos estudos sobre o meio ambiente.

Leff (2008, pp.56-57) entende que a problemática ambiental "abriu um processo de transformação do conhecimento, expondo a necessidade de gerar um método para pensar de forma integrada e multivalente os problemas globais e complexos, assim como a articulação de processos de diferente ordem de materialidade".

Contudo, as ações do homem na Terra e suas repercussões no ambiente têm apresentado uma variação na escala temporal, bem como em relação a regiões e culturas (Drew, 1995).

Só a partir do final do século XIX e início do século XX, surgiram as primeiras ideias acerca da importância da criação de áreas protegidas. Estas surgiram com o objetivo de preservar o ambiente natural, visando produzir um maior benefício à sociedade humana, mantendo seu potencial de satisfazer as necessidades e aspirações das futuras gerações, garantindo e restringindo o uso indevido nas áreas nas quais se aplicam medidas restritivas de uso do solo, com a função de proteção destas áreas dos eventuais impactos ambientais

No Brasil, a primeira referência acerca da possibilidade de criação de uma área protegida foi feita em 1876, pelo engenheiro André Rebouças, que influenciado pela criação do Yellowstone National Park, nos Estados Unidos, publicou um trabalho que fazia referência a proposta de criação de dois Parques Nacionais: o de Sete Quedas e o da Ilha do Bananal.

No entanto, sua proposta não foi aceita naquele momento (Morsello, 2008). Dentre os diferentes tipos de áreas protegidas, destacam-se as Unidades de Conservação (UCs), que são áreas instituídas pelo poder público, com o objetivo de assegurar a proteção da biodiversidade, dos ecossistemas e da paisagem natural. A definição legal de "Unidades de Conservação (UCs)" na legislação brasileira, encontra-se no artigo $2^{\circ}$, inciso I, da Lei Federal n ${ }^{\circ}$ 9.985/2000, que instituiu o Sistema Nacional de Unidades de Conservação da Natureza (SNUC).

No contexto da geografia, o estudo das unidades de conservação é fundamental para se compreender as relações entre sociedade-natureza, tendo como foco o estudo dos territórios, considerando que sua existência repercute na dinâmica socioespacial. 
Apesar dos objetivos conservacionistas, muitas UCs têm sofrido com diversos impactos ambientais, principalmente aquelas próximas ou que se encontram inseridas em áreas urbanas (Ballarotti, 2005; Rocha, 2006; Guerra e Coelho, 2009; Souza, 2011; Arce et al., 2014).

Entende-se que o impacto ambiental é "a alteração da qualidade ambiental que resulta da modificação de processos naturais ou sociais provocada por ação humana" (Sánchez, 2013, p.32), portanto, podendo ser positivo ou negativo, de acordo com a ação humana empreendida numa determinada área.

O Parque Natural Municipal de Cabedelo (PNMC) surge como exemplo de uma unidade de conservação localizada em uma área urbana, que possui grande relevância ecológica e beleza cênica natural, necessitando do plano de manejo para que seus usos sejam regulamentados a fim de minimizar a ocorrência de impactos ambientais.

A partir desta percepção, é imprescindível harmonizar as atividades humanas com a proteção ambiental para que possa haver sustentabilidade e conservação das funções ecológicas dos ecossistemas, como também que a população possa desfrutar e desenvolver atividades legalmente permitidas no interior da UC.

No entanto, o que se observa é que o PNMC tem sofrido com a falta de integração com as populações que residem no seu entorno e a falta de implementação de ações por parte do poder público, gerando um aumento da pressão antrópica sobre essa área.

Sendo assim, o presente trabalho tem o objetivo de analisar os impactos ambientais identificados no interior e no entorno do Parque Natural Municipal de Cabedelo, que é uma unidade de conservação que abriga um importante patrimônio natural de restinga, encravada na área urbana do município de Cabedelo, estado Paraíba, na região Nordeste do Brasil. Autores como Marques (2008) e Lima (2015) desenvolveram trabalhos tendo como objeto o Parque Natural Municipal de Cabedelo, sendo os resultados obtidos por Lima (2015) a serem apresentados e discutidos neste artigo.

Para alcançar tal objetivo foram caracterizadas as principais atividades humanas no entorno do PNMC, bem como foram identificados os principais impactos ambientais, resultando na proposição de ações e possíveis medidas mitigadoras para a minimização ou eliminação dos impactos 
ambientais identificados, à luz do Sistema Nacional de Unidades de Conservação da Natureza (SNUC).

A importância do estudo se reveste no fato das constantes ameaças sofridas pelas Unidades de Conservação, especialmente aquelas localizadas nas áreas urbanas de diversas cidades brasileiras, bem como para expor a inércia que o poder público municipal, enquanto gestor do PNMC, demonstra, ao não implementar o plano de manejo, na deficiência ou ausência da fiscalização ambiental, falta de sinalização da UC, bem como no estímulo e na implementação de ações que estimulem e favoreçam ao aproveitamento racional desse tipo de área protegida, seja por meio da pesquisa científica, da educação ambiental, do lazer, do turismo, assim como dos serviços ecossistêmicos, que refletirão em benefícios para os meios físico e biológico, bem como para a população, principalmente os moradores das comunidades próximas.

\section{Enquadramento Teórico-Conceitual}

De forma breve, no intuito de expor a importância das Unidades de Conservação, apresenta-se um rápido histórico da criação das UCs, especialmente no Brasil, destacando a Lei Federal $n^{\circ}$ 9.985/2000 e o enquadramento das diferentes categorias de UC, enfatizando a categoria Parque, correlacionando às diretrizes aplicáveis a essa categoria em relação ao que se analisou no presente artigo.

\section{Unidade de Conservação: exemplo de área protegida}

Segundo a União Internacional para a Conservação da Natureza UICN (1994), as áreas protegidas são "áreas terrestres ou marinhas claramente definidas, dedicadas à proteção e manutenção da diversidade biológica e dos recursos naturais e culturais associados, com o fim de obter a conservação ao longo do tempo da natureza com os serviços associados ao ecossistema e os valores culturais".

Estão enquadradas nesta definição, não somente as Unidades de Conservação (UCs), mas também as Áreas de Preservação Permanente (APPs), Reservas Legais (RLs), Reservas Indígenas (RIs), Reservas da Biosfera (RBs), Sítios de Proteção criados a partir de convenções e tratados internacionais, Sítios do Patrimônio da Humanidade, entre outras.

Em relação ao tratamento constitucional da questão ambiental, só com a promulgação da Constituição Federal de 1988 que o meio ambiente 
ganhou um capítulo exclusivo, ao contrário das constituições anteriores que nada traziam de específico acerca do assunto. Portanto, o artigo 225 enuncia que: "todos têm direito ao meio ambiente ecologicamente equilibrado, bem de uso comum do povo e essencial à sadia qualidade de vida, impondo-se ao Poder Público e à coletividade o dever de defendê-lo e preservá- lo para as presentes e futuras gerações" (Brasil, 1988).

No inciso III, $\S 1^{\circ}$ do art. 225 , a Constituição garantiu que o meio ambiente ecologicamente equilibrado é condição de direito fundamental da pessoa humana, assegurando e determinando ao Poder Público “[...] definir, em todas as unidades da Federação, espaços territoriais e seus componentes a serem especialmente protegidos, sendo a alteração e a supressão permitidas somente através de lei[...]".

Dessa forma, a Constituição criou uma nova categoria de bem: o bem ambiental, portanto, um bem de uso comum do povo, e, ainda, um bem essencial à sadia qualidade de vida da população. Assim, ninguém tem o direito de causar danos ao meio ambiente, pois se o fizer estará destruindo um bem de todos.

Nessa mesma linha de raciocínio, o inciso III do $\S 1^{\circ}$, garante a manutenção de espaços territorialmente protegidos em todas as unidades da federação, e afirma que a criação dessas áreas deve melhorar as condições de vida humana, pela manutenção de espaços naturais ocupados por espécies animais e vegetais.

Fica entendido, portanto, que essas diretrizes legais formaram, ao longo do tempo, um importante cabedal de sustentação em prol do meio ambiente, porém, só após a promulgação da Lei Federal n n 9.985/2000, foi possível estabelecer critérios e normas para a criação, implantação e gestão das unidades de conservação no Brasil, com a criação do Sistema Nacional de Unidades de Conservação da Natureza (SNUC).

Sistema Nacional de Unidade de Conservação da Natureza (SNUC)

Nota-se que, além da relevância natural e do oficialismo, a lei estabelece o pressuposto da delimitação territorial, realizada através do georreferenciamento dos limites da UC proposta, visando à especificação do espaço a ser resguardado. 
Assim, o território da UC, enquanto espaço legalmente protegido, pode ser usado direta ou indiretamente, garantindo o envolvimento da sociedade em suas múltiplas territorialidades. Para Santos (2002), o território é o lugar onde ocorrem todas as ações, todas as paixões, todos os poderes, todas as forças, todas as fraquezas, onde a história do homem é plenamente realizada a partir das manifestações de sua existência, ou seja, o território é resultado da dinâmica socioespacial.

Nesse sentido, o SNUC procurou assegurar a preservação desses territórios, incluindo seus recursos naturais, habitats, ecossistemas, serviços ecossistêmicos e, em alguns casos, as populações residentes.

Possibilitou também a integração do modo de conduzir a gestão das unidades de conservação, dentro das diferentes esferas de governo, dando um aparato jurídico, técnico e conceitual para que o próprio poder público pudesse criar, de forma legal, esses espaços. O artigo $3^{\circ}$, da Lei Federal $n^{\circ}$ 9.985/2000, afirma que o SNUC é constituído pelo conjunto das unidades de conservação federais, estaduais e municipais.

Segundo o artigo $7^{\circ}$, as UCs são divididas em dois grupos: Unidade de Conservação de Proteção Integral (UPI) e Unidade de Conservação de Uso Sustentável (UUS). No quadro 1 é possível visualizar as cinco diferentes categorias de UPI, que são áreas que proíbem ou restringem a visitação pública, no entanto, permitem a pesquisa científica, desde que esta ocorra com a devida autorização e observando algumas restrições.

As UCs que integram o grupo de proteção integral têm como regra geral proteger a natureza da interferência humana, sendo que a Estação Ecológica e a Reserva Biológica são as mais restritivas dentre as doze categorias (incluindo as UCs de Uso Sustentável), não admitindo a visitação pública, sendo permitida, apenas, com o objetivo educacional. Já no caso das UCs que se enquadram na categoria "Parque", estas admitem a visitação pública, desde que ocorra sob as normas e restrições estabelecidas no Plano de Manejo da unidade e nas normas estabelecidas pelo órgão responsável por sua administração. 
Quadro 1 - Tipos de uso e ocupação nas UCs de Proteção Integral, segundo a Lei Federal No 9985/2000

\begin{tabular}{|c|c|c|c|c|}
\hline UC Integral & $\begin{array}{l}\text { Posse e } \\
\text { Domínio }\end{array}$ & $\begin{array}{c}\text { Áreas } \\
\text { Particulares }\end{array}$ & $\begin{array}{l}\text { Visitação } \\
\text { Pública }\end{array}$ & $\begin{array}{l}\text { Pesquisa } \\
\text { Científica }\end{array}$ \\
\hline $\begin{array}{l}\text { Estação } \\
\text { Ecológica }\end{array}$ & Público & Desapropriadas & $\begin{array}{c}\text { Proibida (Objetivo } \\
\text { Educacional) }\end{array}$ & $\begin{array}{l}\text { Depende de } \\
\text { Autorização }\end{array}$ \\
\hline $\begin{array}{l}\text { Reserva } \\
\text { Biológica }\end{array}$ & Público & Desapropriadas & $\begin{array}{l}\text { Proibida (Objetivo } \\
\text { Educacional) }\end{array}$ & $\begin{array}{l}\text { Depende de } \\
\text { Autorização }\end{array}$ \\
\hline $\begin{array}{c}\text { Parque } \\
\text { Nacional }\end{array}$ & Público & Desapropriadas & $\begin{array}{c}\text { Permitida } \\
\text { (com restrições) }\end{array}$ & $\begin{array}{c}\text { Depende de } \\
\text { Autorização } \\
\text { (com restrições) }\end{array}$ \\
\hline $\begin{array}{c}\text { Monumento } \\
\text { Natural }\end{array}$ & $\begin{array}{l}\text { Público/ } \\
\text { Particular }\end{array}$ & $\begin{array}{c}\text { Desapro- } \\
\text { priadas/ Não } \\
\text { desapropriadas }\end{array}$ & $\begin{array}{c}\text { Permitida } \\
\text { (com restrições) }\end{array}$ & $\begin{array}{c}\text { Depende de } \\
\text { Autorização } \\
\text { (com restrições) }\end{array}$ \\
\hline $\begin{array}{l}\text { Refúgio } \\
\text { da Vida } \\
\text { Silvestre }\end{array}$ & $\begin{array}{l}\text { Público/ } \\
\text { Particular }\end{array}$ & $\begin{array}{c}\text { Desapro- } \\
\text { priadas/ Não } \\
\text { desapropriadas }\end{array}$ & $\begin{array}{c}\text { Permitida } \\
\text { (com restrições) }\end{array}$ & $\begin{array}{c}\text { Depende de } \\
\text { Autorização } \\
\text { (com restrições) }\end{array}$ \\
\hline
\end{tabular}

Org.: Elaboração própria do autor (2020).

As unidades de conservação não devem ser concebidas como áreas intocáveis, pois são ambientes que, além de poderem contribuir com a qualidade de vida da sociedade através dos seus serviços ecossistêmicos, podem ser utilizadas como incremento de atividades relacionadas à pesquisa, a educação, ao turismo e ao lazer, além de proporcionar as futuras gerações um referencial de patrimônio cultural, natural, paisagístico e ecológico.

Completando as dozes categorias de UCs existentes na legislação brasileira, o quadro 2 expõe as sete categorias de UCs de Uso Sustentável, onde a visitação pública e a pesquisa científica são possíveis, de acordo com os casos previstos.

A novidade desse grupo é que algumas UCs podem ser estabelecidas em áreas de domínio privado, não sendo necessária a desapropriação de suas terras. No caso das Áreas de Proteção Ambiental (APAs), estas são áreas, em geral, extensas e podem abranger partes do território de mais de um município, por exemplo. Já as Reservas Particulares do Patrimônio Natural (RPPNs) são de posse e domínio, exclusivamente, particulares, não existindo restrições quanto ao tamanho da propriedade a ser definida como RPPN.

O município de Cabedelo abriga três Unidades de Conservação: a Floresta Nacional da Restinga de Cabedelo, o Parque Estadual Marinho de 
Wendel Pereira de Lima, Henrique Elias Pessoa-Gutierres

Impactos ambientais no Parque Natural Municipal de Cabedelo-Estado do Paraiba (PB), Brasil.

Quadro 2 - Tipos de uso e ocupação nas UCs de Uso Sustentável, segundo a Lei Federal No 9985/2000

\begin{tabular}{|c|c|c|c|c|}
\hline $\begin{array}{l}\text { Unidades de Uso } \\
\text { Sustentável }\end{array}$ & $\begin{array}{l}\text { Posse e } \\
\text { Domínio }\end{array}$ & $\begin{array}{c}\text { Áreas } \\
\text { Particulares }\end{array}$ & $\begin{array}{l}\text { Visitação } \\
\text { Pública }\end{array}$ & $\begin{array}{l}\text { Pesquisa } \\
\text { Científica }\end{array}$ \\
\hline $\begin{array}{l}\text { Área de Proteção } \\
\text { Ambiental (APA) }\end{array}$ & $\begin{array}{l}\text { Público / } \\
\text { Particular }\end{array}$ & $\begin{array}{l}\text { Restrições de } \\
\text { Uso }\end{array}$ & Permitida & Permitida \\
\hline $\begin{array}{l}\text { Área de Relevante } \\
\text { Interesse Ecológico } \\
\text { (ARIE) }\end{array}$ & $\begin{array}{l}\text { Público / } \\
\text { Particular }\end{array}$ & $\begin{array}{l}\text { Restrições de } \\
\text { Uso }\end{array}$ & $\begin{array}{c}\text { Permitida } \\
\text { (com restrições) }\end{array}$ & $\begin{array}{c}\text { Depende de } \\
\text { Autorização } \\
\text { (com restrições) }\end{array}$ \\
\hline $\begin{array}{l}\text { Floresta } \\
\text { Nacional }\end{array}$ & Público & $\begin{array}{l}\text { Desapropriadas } \\
\text { (Exceto Po- } \\
\text { pulações } \\
\text { Tradicionais) }\end{array}$ & $\begin{array}{c}\text { Permitida } \\
\text { (com restrições) }\end{array}$ & $\begin{array}{c}\text { Depende de } \\
\text { Autorização } \\
\text { (com restrições) }\end{array}$ \\
\hline $\begin{array}{c}\text { Reserva } \\
\text { Extrativista }\end{array}$ & Público & Desapropriadas & $\begin{array}{c}\text { Permitida } \\
\text { (com restrições) }\end{array}$ & $\begin{array}{c}\text { Depende de } \\
\text { Autorização } \\
\text { (com restrições) }\end{array}$ \\
\hline $\begin{array}{l}\text { Reserva de } \\
\text { Fauna }\end{array}$ & Público & Desapropriadas & $\begin{array}{c}\text { Permitida } \\
\text { (com restrições) }\end{array}$ & $\begin{array}{c}\text { Depende de } \\
\text { Autorização } \\
\text { (com restrições) }\end{array}$ \\
\hline $\begin{array}{c}\text { Reserva de } \\
\text { Desenvolvimento } \\
\text { Sustentável }\end{array}$ & Público & $\begin{array}{l}\text { Desapropria- } \\
\text { das (quando } \\
\text { necessário) }\end{array}$ & $\begin{array}{c}\text { Permitida } \\
\text { (com restrições) }\end{array}$ & $\begin{array}{c}\text { Depende de } \\
\text { Autorização } \\
\text { (com restrições) }\end{array}$ \\
\hline $\begin{array}{l}\text { Reserva Particu- } \\
\text { lar do Patrimônio } \\
\text { Natural (RPPN) }\end{array}$ & Particular & $\begin{array}{c}\text { Não } \\
\text { desapropriadas }\end{array}$ & $\begin{array}{c}\text { Permitida } \\
\text { (com restrições) }\end{array}$ & Permitida \\
\hline
\end{tabular}

Org.: Elaboração própria do autor (2020).

Areia Vermelha e o Parque Natural Municipal de Cabedelo. A primeira é administrada pelo Instituto Chico Mendes de Conservação da Biodiversidade (ICMBio) - órgão federal, a segunda pela Superintendência de Administração do Meio Ambiente (SUDEMA) - órgão estadual, e a terceira é administrada pela Prefeitura Municipal de Cabedelo.

O Parque Natural Municipal de Cabedelo submete-se aos critérios e normas de implantação e gestão definidos pelo SNUC para as UCs da categoria "Parque". Dessa forma, a Lei Federal no 9.985/2000 dispõe que:

Art. 11. O Parque Nacional tem como objetivo básico a preservação de ecossistemas naturais de grande relevância ecológica e beleza cênica, possibilitando a realização de pesquisas científicas e o desenvolvimento de atividades de educação e interpretação ambiental, de recreação em contato com a natureza e de turismo ecológico. 
Verifica-se que os parques são criados com fins de conservação, pesquisa e turismo. Conforme demonstrado no quadro 1, tal criação acontece em terras de posse e domínio públicos, ou em áreas particulares, que devem ser desapropriadas para esse fim.

As atividades de "pesquisa científica", "atividades de educação e interpretação ambiental", "de recreação em contato com a natureza" e de "turismo ecológico" são perfeitamente viáveis de serem implementadas em qualquer parque (federal, estadual ou municipal), desde que sejam atendidas as boas práticas previstas na legislação e na literatura técnicocientífica para essa categoria de UC.

\section{Metodologia}

O trabalho pautou-se numa perspectiva qualitativa-descritiva com o objetivo de detalhar um problema a ser investigado, permitindo uma melhor compreensão do mesmo. Optou-se pelo método sistêmico, que na Geografia tem derivado em outros métodos, a exemplo da noção de paisagem, ecogeografia e geossistemas.

O trabalho é alicerçado no método geossistêmico, criado pelo soviético Sotchava, em 1962, fazendo uso dos princípios sistêmicos e da noção de paisagem, expressando a conexão entre natureza e sociedade (Guerra e Marçal, 2006). Os geossistemas correspondem ao resultado da combinação dos fatores geomorfológicos, climáticos, hidrológicos e da cobertura vegetal, além de agregar fatores sociais e econômicos. É também o resultado de uma relação imbricada de diversos fatores que interferem uns sobre os outros e que variam no tempo e no espaço (Christofoletti, 1999).

Entende-se que "o importante no conhecimento não é a sua condição de produto, mas o seu processo (...) o saber não pode acontecer na fragmentação, deverá acontecer, sob a perspectiva da totalidade" (Costa, 2012, p. 80).

Diante do panorama acima traçado, entende-se que a interdisciplinaridade deve estar vinculada as questões socioambientais, levando em conta os diversos aspectos de formação social. Sendo assim, o geógrafo necessita utilizar os conhecimentos de outras ciências, o que exige uma capacidade para reunir diferentes tipos de conhecimento relativos ao espaço (Mendonça, 1989). 
Wendel Pereira de Lima, Henrique Elias Pessoa-Gutierres

Impactos ambientais no Parque Natural Municipal de Cabedelo-Estado do Paraiba (PB), Brasil.

\section{Procedimentos metodológicos}

Os procedimentos metodológicos adotados para o cumprimento do objetivo traçado consistiram no levantamento e na análise bibliográfica, trabalhos de campo para a execução de registros fotográficos, observações in loco, aplicação de questionários, validação de dados e pesquisa documental em órgãos públicos (Ministério Público Estadual e na Prefeitura Municipal de Cabedelo).

Inicialmente, para a avaliação das condições do parque, obteve-se a percepção das moradoras, por meio da aplicação dos questionários, sendo, posteriormente, a partir do que foi levantamento e sistematizado, realizadas incursões no entorno e no interior do PNMC, no intuito de verificar e validar a percepção das moradoras, como também outros aspectos não contemplados nas respostas dos questionários, mas com base na percepção dos autores do estudo.

A identificação das atividades humanas impactantes, através da observação in loco, objetivou a obtenção de dados da realidade do PNMC. Também foram encaminhados ofícios solicitando dados à Secretaria $\mathrm{Mu}$ nicipal de Meio Ambiente e Pesca de Cabedelo (obtenção do Decreto de criação do Parque Natural Municipal de Cabedelo); e ao Ministério Público Estadual (sobre procedimentos abertos referentes a possíveis denúncias sobre os problemas ambientais no Parque Natural Municipal de Cabedelo).

Os questionários semiestruturados foram aplicados junto às moradoras do bairro Jardim Manguinhos. O total de entrevistadas foi de 18 pessoas, que representa $0,1 \%$ do total de domicílios particulares ocupados no município de Cabedelo, tomando como sujeitos as donas-de-casa, de acordo com a metodologia adotada por Jacobi (1999), ou seja, donas de casa que residem na comunidade.

A escolha pela percepção das moradoras teve como referência o pensamento de Leff (2008), de que uma questão importante para a análise da qualidade de vida é a percepção, pelo próprio sujeito, de suas condições de existência. Ou seja, buscou-se no trabalho medições objetivas através de percepções subjetivas, onde a concepção e a constituição desses indicadores multicriteriais e interprocessuais se defrontam com a incomensurabilidade desses processos (Leff, 2008).

Com relação ao total de questionários que seriam aplicados, procedeu-se a determinação da amostragem das pessoas entrevistadas, tendo 
como parâmetro $0,1 \%$ do total de "Domicílios Particulares Ocupados", constante no Censo Demográfico 2010 do Instituto Brasileiro de Geografia e Estatística (IBGE).

Na parte inicial, o questionário tratou do perfil sociodemográfico das participantes (idade, tempo de residência, naturalidade, nível de instrução e renda) e das ações/atividades referentes ao cotidiano, associadas às condições de vida dos moradores (abastecimento d'água, rede de esgoto e resíduos sólidos), da geração de impactos para o PNMC (poluição do ar e sonora) e da relação da comunidade com a UC.

No tocante às questões sobre o abastecimento de água, as entrevistadas foram questionadas sobre a "origem da água usada pelas pessoas da comunidade" (Rede Pública, Fonte Privada, Fonte Coletiva ou Rios); "qualidade da água" (se boa ou ruim); a "regularidade do fornecimento" (se constante ou falta); e se "a comunidade acaba utilizando algum corpo d'água (rio, riacho, etc.) para suprir a falta de água".

Sobre a rede de esgoto, as moradoras foram questionadas sobre o destino dos efluentes domésticos (rede de esgoto; fossas sépticas; dentro do PNMC; ou no rio ou mangue).

Para os resíduos sólidos foram feitas perguntas sobre a existência da coleta por parte do poder público municipal e a frequência do serviço (diariamente; até duas vezes por semana; três vezes por semana), como também "a forma de armazenamento do lixo depositado fora de casa (se em coletores apropriados fechados; recipiente abertos não apropriados; nas bordas do PNMC; dentro do PNMC; em ruas e avenidas; ou em outros locais).

Na percepção sobre a poluição do ar, questionou-se se "existe poluição do ar na área da comunidade" e "qual o principal tipo de emissão (emissão de poluentes provenientes da queima de lixo; mau cheiro; fumaça proveniente da queima de madeira). Por fim, no tocante à ocorrência de poluição sonora na área da comunidade, tal aspecto foi questionado a respeito de "quais os principais emissores (indústria; trânsito; vizinhos; outros).

Para se obter a percepção da comunidade em relação ao PNMC, o questionário contemplou algumas questões específicas da relação entre a "Comunidade e o Parque Natural Municipal de Cabedelo": 
- Em sua opinião, qual é a importância do Parque Natural Municipal de Cabedelo para a comunidade? (Muito importante; Sem importância)

- Você considera que a situação ambiental no Parque Natural Municipal de Cabedelo nos últimos anos (Melhorou; Permaneceu a mesma; Piorou; Piorou muito)

- $\quad$ Na sua opinião, qual (is) os problema (s) do Parque Natural Municipal de Cabedelo? (Falta de fiscalização; Falta de segurança; Deposição de lixo; Queimadas; Retirada de madeira; Retirada de areia; outros)

- $\quad$ O que você acha que precisa ser feito para melhorar a conservação do Parque Natural Municipal de Cabedelo?

- Os familiares que estudam em escolas do bairro já visitaram o Parque? Quem promoveu a visita?

- $\quad$ Algum morador ou a comunidade já fez alguma reclamação a Prefeitura Municipal de Cabedelo ou ao Ministério Público para denunciar problemas ambientais na área do Parque Natural Municipal de Cabedelo?

A partir do preenchimento dos questionários aplicados, os dados foram sistematizados por meio de planilha eletrônica, com o objetivo de quantificar as respostas dadas.

\section{Área de Estudo}

O município de Cabedelo está localizado na microrregião de João Pessoa e na mesorregião da Mata Paraibana. Situado entre as coordenadas $6^{\circ} 57^{\prime} 56^{\prime \prime} \mathrm{S}$ e $7^{\circ} 05^{\prime} 59^{\prime}$ ' S e $34^{\circ} 49^{\prime} 31^{\prime \prime} \mathrm{W}$ e $34^{\circ} 51^{\prime} 57^{\prime}$ ' W, é caracterizado por ser uma restinga arenosa (Figura 1). Tem como limites, a leste e a norte, o oceano Atlântico, a oeste o estuário do rio Paraíba e ao sul, o rio Jaguaribe e a cidade de João Pessoa.

O município integra a Região Metropolitana de João Pessoa (conforme o artigo $1^{\circ}$ da Lei Estadual Complementar $n^{\circ} 59$, de 30 de dezembro de 2003). Enquanto município litorâneo, Cabedelo compreende a continuidade, ao norte, da orla da cidade de João Pessoa e estreita-se no encontro do rio Paraíba com o mar. Possui uma área de, aproximadamente, $33 \mathrm{~km}^{2}$, com $12 \mathrm{~km}$ de extensão por $3 \mathrm{~km}$ em sua maior largura (Pimentel, 2001), representando $0,0554 \%$ da área total do estado e $0,0004 \%$ do território brasileiro. 
Figura 1 - Mapa de localização do município de Cabedelo, Paraíba, Brasil

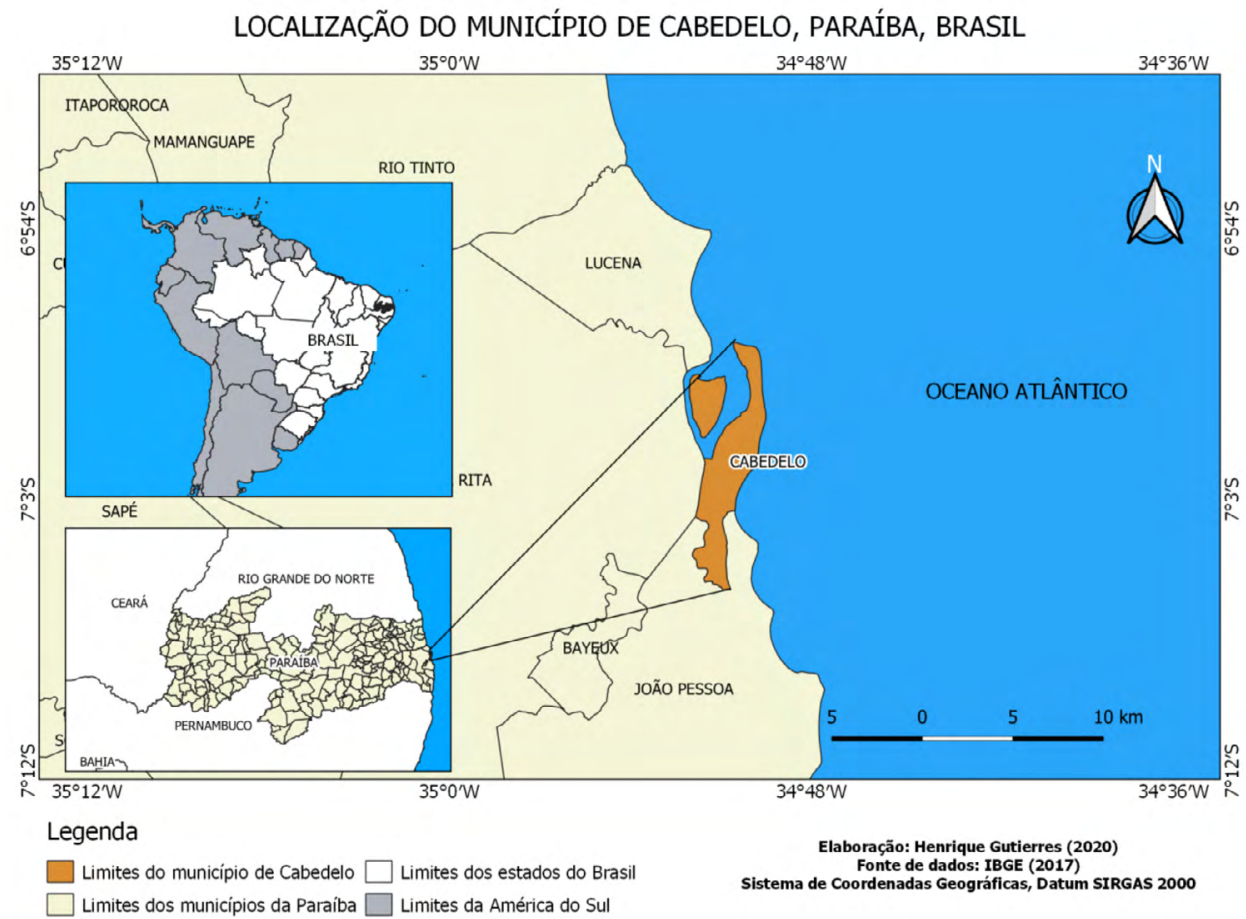

Fuente: Elaboração própria do autor (2020).

O município possui um clima quente e úmido, apresentando um período chuvoso no meio do ano (maio, junho e julho) e outro seco (setembro, outubro e novembro), no qual se verificam os maiores déficits de pluviosidade anual. A área é formada por sedimentos areno-quartzosos não consolidados, muito profundos, ácidos e, com pouca ou quase nenhuma vocação agrícola, constituída por sedimentos aluviais Cenozoicos. Verifica-se a ocorrência de depósitos quaternários (terraços marinhos pleistocênicos, terraços marinhos holocênicos, depósitos de mangues e depósitos aluvial).

Do ponto de vista hidrográfico, encontra-se inserido nos domínios da bacia hidrográfica do rio Paraíba, região do baixo Paraíba. Desta forma, todos os seus cursos de água tem características de regime de escoamento perene e seu padrão de drenagem é o dendrítico. 
No tocante aos aspectos demográficos, segundo o Censo Demográfico de 2010 (IBGE), o município possui uma população total de 57.926 habitantes, sendo que 27.623 são homens e 30.303 são mulheres.

O Índice de Desenvolvimento Humano Municipal (IDHM) é de 0.748 , ocupando a $583^{\mathrm{a}}$ posição entre os 5.565 municípios brasileiros, segundo o Atlas do Desenvolvimento Humano do Brasil (2010). Ainda de acordo com o IBGE (2010), Cabedelo contabiliza um total de 16.228 domicílios, sendo 10.865 domicílios particulares permanentes, dos quais $97,12 \%$ são atendidos pela rede geral de distribuição de água, $92 \%$ são atendidos pelo serviço de coleta de lixo, porém nenhum por rede de esgoto.

\section{Parque Natural Municipal de Cabedelo - PNMC}

O Parque Natural Municipal de Cabedelo foi criado pelo Decreto Municipal $n^{\circ} 12$, de 16 de abril de 2003 e está situado no perímetro urbano (Figura 2), localizado entre as coordenadas 6 $659^{\prime} 55^{\prime}$ " S a $7^{\circ} 00^{\prime} 42^{\prime \prime} \mathrm{S}$ e entre as coordenadas $34^{\circ} 49^{\prime} 47^{\prime}$ ' W e $34^{\circ} 50^{\prime} 06^{\prime}$ ' W, ocupando uma área de aproximadamente 52,12 hectares. Encontra-se situado entre o mar e a rodovia federal BR-230, que margeia o PNMC (lado esquerdo da foto), enquanto que no lado direito, o rio Paraíba se destaca na paisagem.

Figura 2 - O Parque Natural Municipal de Cabedelo (área verde no centro da foto), a urbanização no seu entorno com bairros residenciais,

Oceano Atlântico (esquerda) e o rio Paraíba (direita)

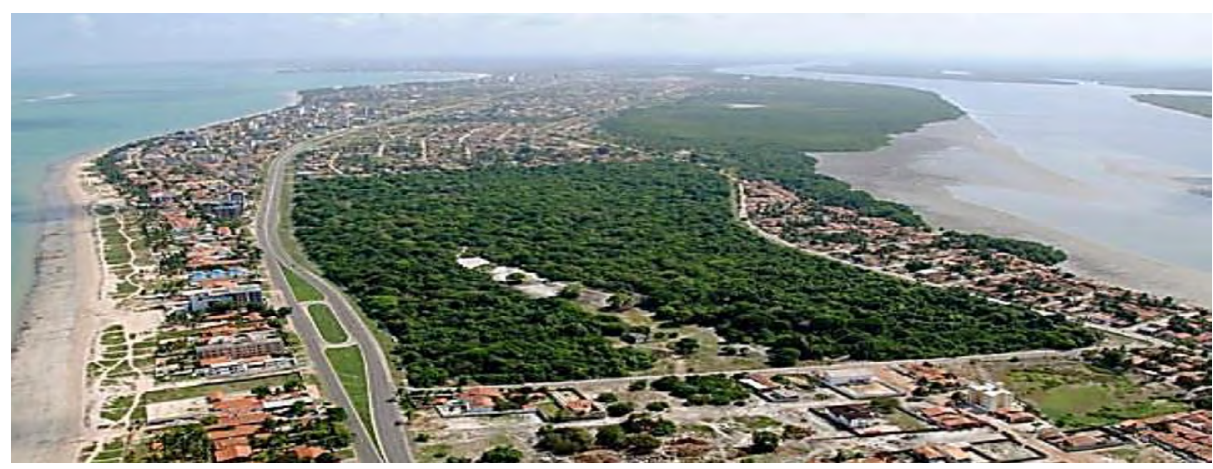

Foto: Petrúcio Carlo (2017).

O decreto de criação do PNMC elencou os seguintes objetivos: I - preservar a biodiversidade e os ecossistemas naturais, admitindo-se apenas o uso indireto e controlado dos recursos; II - proteger espécies novas, 
endêmicas, vulneráveis ou em perigo de extinção; III - possibilitar a realização de estudos, pesquisas e trabalhos de interesse científico; IV - proteger a beleza cênica e paisagística (Decreto Municipal $\mathrm{n}^{\circ} 12$, de 16 de abril de 2003).

No entanto, após mais de uma década de criação, o local ainda não dispõe de um plano de manejo, descumprindo o inciso III, do artigo 27, da Lei Federal no 9.985/2000, que estabelece que o plano de manejo é obrigatório para todas as unidades de conservação e a sua elaboração deve ocorrer em até cinco anos após sua criação.

De acordo com a Lei do SNUC, o Plano de Manejo é o documento técnico mediante o qual, com fundamento nos objetivos gerais de uma unidade de conservação, se estabelece o seu zoneamento e as normas que devem presidir o uso da área e o manejo dos recursos naturais, inclusive a implantação das estruturas físicas necessárias à gestão da unidade. Nesse contexto, a elaboração do plano de manejo do PNMC deverá considerar os preceitos estabelecidos pela Lei do SNUC, em consonância com as políticas públicas, o desenvolvimento e a conservação do patrimônio natural.

Moura e Costa (2009), estudando o Parque Estadual da Pedra Branca, encravado na área urbana do Rio de Janeiro, apontam que após mais de 30 anos da criação da unidade, o parque ainda não contava com um plano de manejo legalmente instituído e não legalizou a situação das terras particulares inseridas nos seus limites, "o que torna sua gestão altamente conflitante com diversos interesses" (Moura e Costa, 2009, p.232), o que vem acarretando na perda de parte da sua cobertura vegetal original.

Já Coelho Neto et al. (2009) destacam o exemplo do Parque Nacional da Tijuca no Rio de Janeiro, quando, no ano de 1976, foi aprovado o Decreto Municipal no 322/1976, que estabeleceu o zoneamento urbanístico e criou uma faixa de proteção no entorno do parque.

O PNMC encontra-se situado no bairro de Jardim Manguinhos, antigo "Sitio do Boi", tendo tal bairro iniciado a sua ocupação no início na década de 1950, como resultado da expansão do bairro de Camalaú, que está situado a oeste do Parque Natural Municipal de Cabedelo. A história da comunidade está diretamente ligada com a antiga Mata do Estado, atual Parque Natural Municipal de Cabedelo.

Inicialmente, a comunidade foi formada por pescadores, catadores de caranguejos, marisqueiras e trabalhadores do setor terciário que residiam 
em localidades próximas ao bairro. Em meados dos anos de 1980, o local foi beneficiado com as obras do Projeto Mutirão, financiado pelo Governo do Estado da Paraíba, que transformou as antigas casas de taipa em casas de alvenaria com infraestrutura básica para a comunidade.

\section{Resultados}

\section{Caracterização dos Moradores e dos Domicílios}

Para um melhor entendimento das atividades humanas e dos impactos ambientais que vem ocorrendo no Parque Natural Municipal de Cabedelo, realizou-se um levantamento socioeconômico das moradoras do bairro de Jardim Manguinhos, consistindo em reunir dados que evidenciassem os vários fatores que podem contribuir para o processo de degradação dos recursos naturais do PNMC. A tabela 3 apresenta um panorama dos dados obtidos junto às entrevistadas.

Tabela 3 - Caracterização socioeconômica das moradoras residentes no entorno do PNMC

\begin{tabular}{c|c}
\hline Média etária das entrevistadas & 44 anos \\
\hline Naturalidade & $\begin{array}{c}\text { Cabedelo (44,4\%); João Pessoa; }(16,6 \%) ; \text { Pernambuco } \\
(16,6 \%) ; \text { Santa Rita; }(5,6 \%) ; \text { Lucena; }(5,6 \%) ; \text { Esperança } \\
(5,6 \%) ; \text { Rio de Janeiro }(5,6 \%)\end{array}$ \\
\hline Nível de instrução & $\begin{array}{c}\text { Sem instrução (5,6\%); Ensino Fundamental I incompleto } \\
(5,6 \%) ; \text { Ensino Fundamental II incompleto (27,8\%); } \\
\text { Ensino Fundamental II completo (0\%); Ensino Médio } \\
\text { incompleto (33,2\%); Ensino Médio completo (22,2\%); } \\
\text { Superior incompleto (0\%) Superior Completo (5,6\%); } \\
\text { Superior com Pós-Graduação (0\%). }\end{array}$ \\
\hline $\begin{array}{c}\text { Rendimento médio mensal } \\
\text { familiar }\end{array}$ & 1,7 salários mínimos \\
\hline
\end{tabular}

Fonte: Trabalho de campo.

Foram entrevistadas moradoras com idades entre 20 e 67 anos, sendo que $16,7 \%$ tinham idades de 20 a 29 anos, $22,2 \%$ possuíam de 30 a 39 anos, $44,4 \%$ tinham mais de 40 e menos que 60 anos, já $16,7 \%$ tinha idade superior a 60 anos. Cerca de $61 \%$ das entrevistadas são naturais das cidades de Cabedelo e João Pessoa, enquanto que 39\% de outras localidades.

Apenas 5,6\% das entrevistadas não possuem instrução, sendo que $61 \%$ compreende um universo de moradoras com o médio incompleto, 
médio completo ou o ensino superior completo. Sobre essa questão, uma moradora que reside no local há 34 anos informou que: "antigamente era tudo muito dificil, hoje só não estuda quem não quer, o bairro tem três escolas, e agora no ensino bairro de Camboinha tem o IFPB, fica tão perto que dá pra ir até a pé”.

A média do rendimento familiar das entrevistadas é de 1,7 salários mínimos, sendo que $11,1 \%$ possuem menos de um salário mínimo, 55,6\% possuem renda de um salário mínimo, 5,6\% tem renda de dois salários, $22,2 \%$ recebem entre quatro e cinco salários, e 5,6\% tem renda superior a cinco salários mínimos.

De uma forma geral, todos os domicílios visitados foram casas, sendo que $83 \%$ das entrevistadas possuem residência própria, $11 \%$ moram em casas alugadas e $6 \%$ residem em imóveis cedidos, tendo a média do tempo de residência ficado em 26 anos. O tempo de residência é um fator importante e fundamental para o alcance temporal e a confiabilidade dos depoimentos e das respostas aos questionários.

Assim, foi constatado que o tempo de residência variou de 17 a 45 anos, sendo que $94,4 \%$ das entrevistadas residem no local há mais de 20 anos. Posteriormente, as entrevistadas foram questionadas a respeito dos serviços básicos (abastecimento de água, rede de esgoto e coleta de resíduos sólidos), além da percepção com relação à poluição sonora e atmosférica, conforme exposto a seguir.

Constatou-se que $100 \%$ dos domicílios visitados têm a rede pública como fonte de abastecimento de água. Dessa forma, 100\% das entrevistadas informaram que a qualidade da água era boa, o fornecimento era constante e não utilizavam outros corpos de água para suprir suas necessidades como rios, riachos ou outros.

Por outro lado, $88 \%$ das entrevistadas responderam que utilizam fossas sépticas para lançamento de águas residuais domésticas e $12 \%$ informaram que utilizam o sistema de rede de esgoto. E todas informaram que não jogam resíduos dentro dos rios, do mangue ou do PNMC.

Segundo as entrevistadas, $77,7 \%$ responderam que a coleta do lixo ocorre todos os dias, principalmente no período noturno, 16,7\% informaram que a coleta é realizada três vezes por semana e 5,6\% informaram que esta coleta ocorre apenas duas vezes por semana. 
Algumas moradoras que residem em ruas estreitas, próximas ao mangue, reclamaram que a coleta só é realizada nas ruas principais e que os moradores são obrigados a colocar o lixo na avenida principal para facilitar o recolhimento por parte da prefeitura.

Cerca de $66,6 \%$, das entrevistadas afirmaram que sofrem com problemas relacionados com esse tipo de poluição, sendo a fumaça proveniente da queima de lixo, o mau cheiro e a fumaça resultante da queima de madeira, as principais causas mencionadas.

Do total das entrevistadas, apenas $22,2 \%$ informaram que não sofrem com problemas relacionadas à poluição do ar. Segundo as entrevistadas, a fumaça proveniente da queima de madeira é o principal problema de poluição do ar enfrentado pelos moradores do bairro, atingindo $38,9 \%$ do total, seguido do mau cheiro, que atinge $22,2 \%$ e da fumaça proveniente de queima de lixo que afeta $16,7 \%$ do total, segundo as entrevistadas.

A existência da poluição sonora foi confirmada por $50 \%$ das entrevistadas, sendo restrita ao barulho proveniente de som alto de vizinhos. Esse tipo de poluição pode ser definido como o conjunto de ruídos desagradáveis e perturbadores provocados pela propagação de sons e, dependendo de sua intensidade, podem causar danos irreparáveis aos seves vivos.

A principal característica da poluição sonora é que ela não deixa resíduos no meio, no entanto, pode ser prejudicial à saúde emocional, física e mental dos seres vivos. Alguns animais, quando expostos ao ruído excessivo, fogem de seus locais naturais podendo ser atropelados e mortos em vias públicas e rodovias. Diante da obtenção de um perfil sociodemográfico das moradoras residentes no entorno do PNMC e das práticas dos moradores do bairro, que afetam o meio ambiente, buscou-se entender a relação dos moradores com o PNMC.

\section{Discussão}

\section{Impactos ambientais identificados no interior do PNMC}

Todas as entrevistadas afirmaram que o Parque Natural Municipal de Cabedelo é muito importante para o bairro de Jardim Manguinhos. No entanto, com relação ao cenário de conservação do espaço protegido, um total de $44 \%$ declarou que a situação de conservação do parque "piorou", $28 \%$ "piorou muito" e $28 \%$ considera que "não mudou", não tendo sido 
registrada nenhuma entrevistada que tenha considerado que a conservação da UC tenha melhorado.

A falta de fiscalização e de segurança foram os principais problemas indicados pelas entrevistadas, o que tem contribuído significativamente para todas as outras ações impactantes que ocorrem no interior da UC (Gráfico 1). Vale destacar que a "deposição de lixo" e "Queimadas" são citados pelas entrevistadas, o que confirma os dados referentes às situações de poluição do ar, onde as queimadas foram apontadas como um problema para a comunidade.

Segundo as entrevistadas, para melhorar a conservação do PNMC, a Prefeitura de Cabedelo deveria terminar de cercar o local, disponibilizar vigilância e colocar placas de identificação e de aviso, além de desenvolver um trabalho de educação ambiental na comunidade e nas escolas. Ao serem questionadas se algum morador ou a comunidade já fez alguma reclamação a Prefeitura Municipal de Cabedelo ou ao Ministério Público Estadual para denunciar problemas ambientais na área do Parque Natural Municipal de Cabedelo, todas as entrevistadas informaram que nunca fizeram ou desconhecem qualquer tipo de denúncia dessa natureza.

Gráfico 1 - Principais problemas ambientais que afetam o PNMC, segundo as moradoras do entorno do PNMC

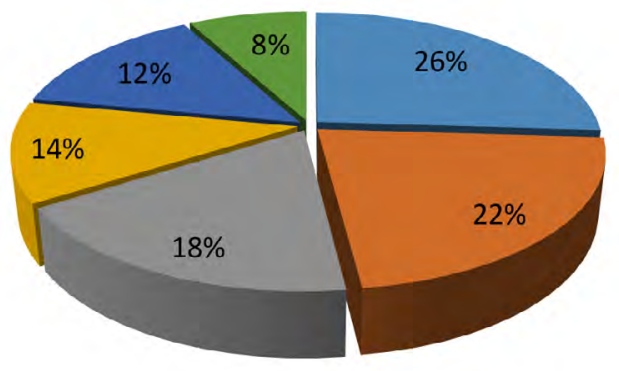

\author{
- Falta de fiscalização \\ - Falta de segurança \\ - Deposição de lixo \\ Q Queimadas \\ - Retirada de madeira \\ netirada de areia
}

Fonte: Trabalho de campo.

Org.: Autores.

A partir dos trabalhos de campo desenvolvidos, constatou-se que o local tem sido alvo de diversas ações impactantes, destacando-se: o corte de madeira, deposição de lixo, incêndios, retirada de areia, descarte de 
entulhos e criação de animais. Portanto, não condizente com aquilo que prevê a legislação ambiental, especialmente as diretrizes estabelecidas pela lei do SNUC e pelo Decreto Municipal de criação do PNMC. A seguir cada ação será detalhada:

Criação de animais: tem ocorrido de forma constante em quatro pontos da UC, sendo dois localizados na porção norte do parque, nos limites da rua João Castor de Sena (antiga rua de barro) no loteamento Vila Madalena, e na lateral da ferrovia da Companhia Brasileira de Trens Urbanos (CBTU) e no bairro Jardim Manguinhos. A criação de animais provoca alterações significativas no ambiente, destacando-se: o impacto visual, compactação do solo e a perda da cobertura vegetal.

Deposição de lixo: foi observado que são descartados dentro do PNMC vários tipos de resíduos. Os mais comuns são materiais sólidos como papéis, latas e plásticos, além de eletrodomésticos (Figuras 3 e 4).

Figuras 3 e 4 - Lixo e entulhos jogados no interior do PNMC
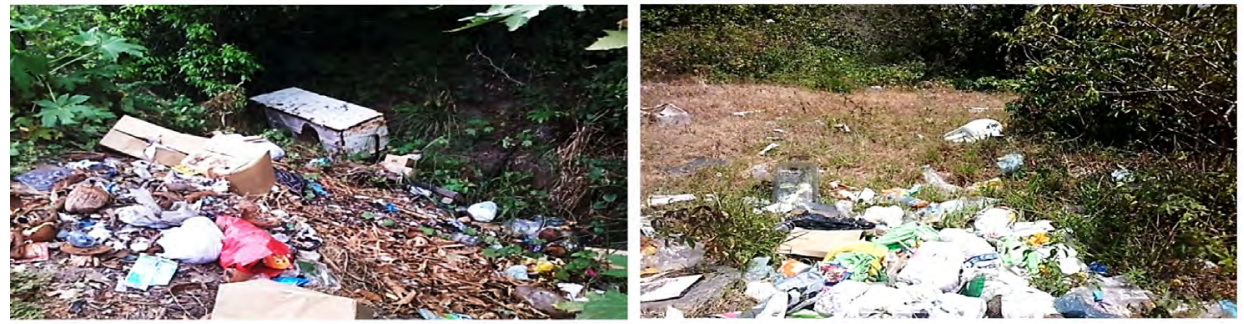

Fonte: Autores.

Ainda sobre essa questão, as pessoas entrevistadas informaram que não utilizam coletores fechados e apropriados para armazenarem o lixo que sai de suas casas, tendo 5,6\% das entrevistadas declarado que descartam o lixo dentro do PNMC, 22,3\% declararam que utilizam recipientes abertos não apropriados, enquanto que $24 \%$ descartam o lixo nas bordas do PNMC e $48,1 \%$ depositam o lixo em ruas ou avenidas.

Constatou-se que alguns moradores não utilizam sacolas, caixas ou qualquer outro recipiente para depositarem seu lixo, levam tudo em carros de mão e deixam nas bordas do PNMC para ser recolhido por caminhões da Prefeitura. 
O descarte não apropriado do lixo tem gerado vários problemas para o PNMC e para a comunidade, pois, além de alterar a paisagem, possibilita o surgimento de focos para várias doenças com a atração de vetores, além da contaminação do solo. Ainda sobre a deposição de resíduos, constatou-se que os animais mortos são jogados dentro do PNMC. Sobre essa questão, 22,2\% das entrevistadas informaram que tem convivido com esse problema.

\section{Retirada de areia}

A retirada de areia do interior do PNMC ocorre, geralmente, no interior da mata de restinga, sendo utilizadas carroças para o transporte do material. Nas figuras 5 e 6 é possível visualizar os locais onde houve a retirada da areia. Essa prática de extração ilegal provoca vários problemas ao meio ambiente, principalmente no tocante ao desencadeamento de processos erosivos, degradação do solo e diminuição da cobertura vegetal, o que não condiz com os objetivos propostos para essa UC, sendo mais uma prova da falta de fiscalização e de ações de conservação pelo poder público.

Figuras 5 e 6 - Locais identificados com a retirada de areia no interior do PNMC
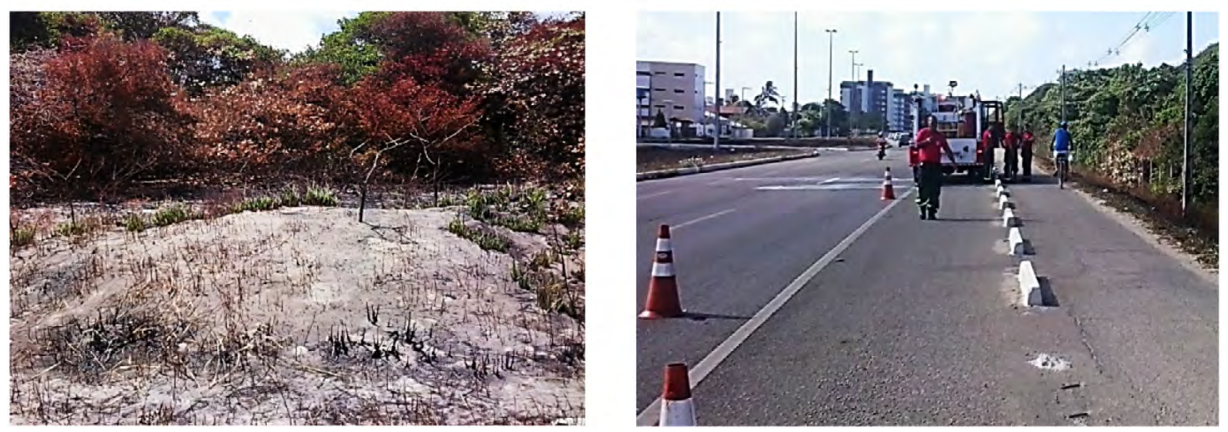

Fotos: Autores.

\section{Incêndios}

O Parque Natural Municipal de Cabedelo também tem sido alvo de incêndios, que são provocados, geralmente, por causas antropogênicas (Figuras 7 e 8), tanto pela presença de ruas e de moradias no seu entorno (limites norte, sul e oeste), como também, em seu limite leste, por ser margeado pela rodovia BR-230. 
Wendel Pereira de Lima, Henrique Elias Pessoa-Gutierres

Impactos ambientais no Parque Natural Municipal de Cabedelo - Estado do Paraiba (PB), Brasil.

Figuras 7 e 8 - Parte da vegetação do PNMC atingida por incêndio e a ação do Corpo de Bombeiros no trecho que se limita com a rodovia BR-230
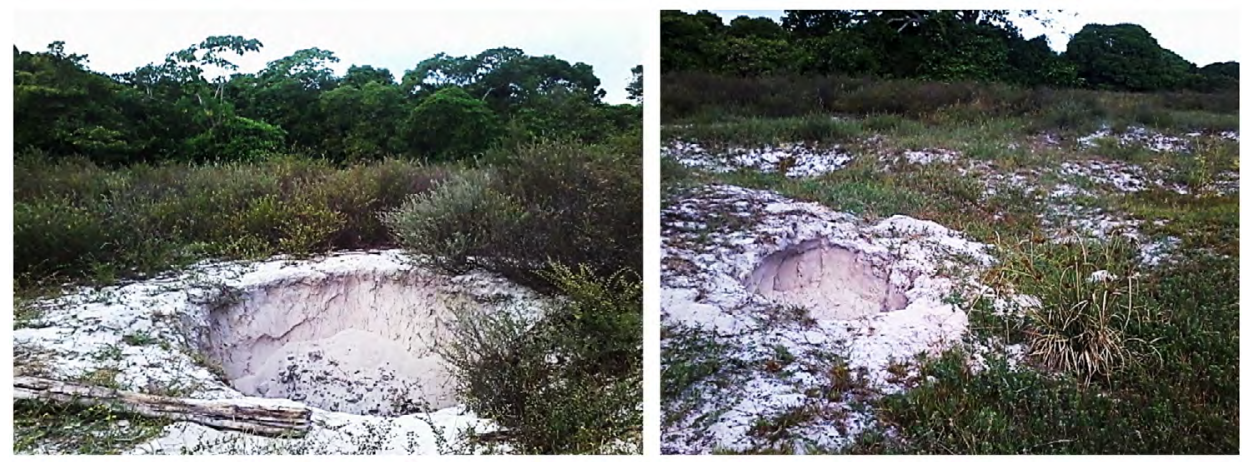

Fotos: Autores.

Tal situação pode acarretar na extinção de espécies nativas, perda dos nutrientes dos solos, proliferação de espécies invasoras, problemas a saúde dos moradores e impacto visual da paisagem.

\section{Retirada de madeira}

A respeito da problemática da retirada de madeira no PNMC (Figura 9), uma moradora informou que esse problema acontece por diversos fatores, dentre os quais o fato de alguns moradores ainda utilizarem a madeira como combustível para cozinhar alimentos.

Uma moradora residente no bairro de Jardim Manguinhos, há mais de 45 anos, afirmou que: "antigamente as pessoas tiravam madeira da mata para construir as casas e para cozinhar, hoje não resta quase nenhuma árvore grande, o povo destruiu quase tudo". Sobre esse assunto ela informou ainda que: "a retirada de madeira do Parque Natural Municipal de Cabedelo ocorre principalmente no mês de junho, período em que são retiradas madeiras para fogueiras de São João".

Morsello (2008, p.248) destaca que "conflitos entre governo e comunidade nascem da disputa pelo controle do território designado como área protegida. Usualmente, isso ocorre nos casos em que o território é propriedade oficial do Estado mas, na realidade, é controlado "de fato" pelos residentes". 
Diante do cenário retratado, concorda-se com as palavras da autora, que para se alcançar os objetivos propostos para as áreas protegidas não é suficiente, apenas, recursos financeiros e conhecimentos dos processos naturais, mas também a implementação de ações relacionadas aos aspectos político-institucionais, como a presença de funcionários bem treinados, infraestrutura no local voltada à fiscalização e a visitação, permitindo a redução de conflitos com a população do entorno.

\section{Considerações finais}

Devido à falta de políticas públicas que assegurem a sustentabilidade ambiental e a conscientização das pessoas que residem no entorno do Parque Natural Municipal de Cabedelo, o local tem sido alvo de diversas ações impactantes provenientes da antropização das áreas que se encontram próximas do bairro de Jardim Manguinhos e da comunidade "Gameleira", que têm contribuído de forma significativa para a degradação ambiental do PNMC, principalmente com a deposição de lixo, queimadas, retirada de madeira e de areia no interior do parque.

Percebe-se que essas localidades não foram contempladas com a instalação de muretas e grades de proteção, que ocorreu apenas na frente da rodovia BR 230 e na lateral norte do parque, o que favoreceu a ocorrência de diversas ações impactantes nessas áreas, que podem ser associadas à falta de infraestrutura, que não possui condições mínimas que assegurem a sua proteção.

Diante das condições de conservação e preservação do Parque Natural Municipal de Cabedelo, constata-se que o poder público municipal tem se mostrado negligente no seu papel de salvaguardar esse importante patrimônio ambiental, especialmente pela ausência e/ou insuficiência de recursos humanos, técnicos e financeiros, o que tem reforçado a percepção por parte da população de que a situação ambiental do PNMC piorou nos últimos anos.

A conservação do PNMC é importante, não apenas para a população local, mas para toda a região circunvizinha, pois a área possui uma relevante beleza cênica e funciona como corredor ecológico para avifauna regional. Juntamente com a Floresta Nacional da Restinga de Cabedelo, constituem as únicas áreas verdes urbanas do município de Cabedelo. 
Logo, deve-se conhecer as potencialidades e as fragilidades da área e se faz necessária uma gestão participativa, que contribua para a gestão de conflitos e a geração de renda por meio do estabelecimento de mecanismos que favoreçam a inserção dos moradores das comunidades.

Enquanto uma UC da categoria parque, são inúmeros os exemplos de Parques Nacionais (Chapada Diamantina, Lençóis Maranhenses, Jericoacoara, Fernando de Noronha, Vale do Catimbau, dentre outros), que possuem um dinamismo no tocante ao aproveitamento turístico, de lazer, de pesquisa científica e com objetivo educacional.

Para o PNMC, enquanto uma UC municipal e encravada numa área urbana, tal desafio é ainda maior. Dessa forma, o município de Cabedelo deverá promover ações buscando a elaboração do plano de manejo, o cercamento da área, a implantação de placas de sinalização, construção de uma área administrativa no interior da unidade com a presença de pessoas responsáveis pela segurança e fiscalização do lugar, além da promoção da pesquisa científica, turismo ecológico e atividades de educação ambiental e recreação, conforme preconiza a lei do SNUC.

O PNMC apresenta grande beleza cênica e relevante importância ecológica. Por localizar-se em uma área urbana, pode contribuir para a conscientização da população sobre a necessidade de conservar o ambiente natural, bem como melhorar o conforto ambiental para os moradores residentes nas suas proximidades.

Sua proteção é extremamente importante no sentido de garantir a preservação dos recursos naturais e dos serviços ecossistêmicos, que contribuem significativamente para a qualidade de vida das comunidades que residem em seu entorno, além de poder servir como ambiente natural de recreação e lazer para as populações urbanas que vivem constantemente em um ambiente constituído por áreas construídas. 
Wendel Pereira de Lima, Henrique Elias Pessoa-Gutierres Environmental impacts in the Cabedelo Municipal Natural Park - State of Paraiba, Brazil.

\section{Referências}

Arce, P. A.; Pendloski, C. J. S.; Oliveira, R. B.; Gallardo, A. L. C. F.; Ruiz, M. S. (2014). Conflitos socioambientais em unidades de conservação em áreas urbanas: o caso do Parque Tizo em São Paulo. Holos, 1(30), pp.75-85.

Assmann, H. (1999). Reencantar à Educação. Petrópolis, Brasil: Vozes.

Ballarotti, L. (2005). Análise das Condições ambientais do Parque Arthur Thomas e sua importância para a população de Londrina $-P R$. Dissertação de mestrado em Geociências, Universidade Estadual de Londrina. Brasil (p.92).

Brasil. (1988). Constituição da República Federativa do Brasil. Brasília, Brasil: Senado.

Brasil (2000), Lei n ${ }^{\circ}$ 9.985, de 18 de julho de 2000. Recuperado de: http:// www.planalto.gov.br/ccivil_03/leis/L9985.htm. Acesso em: 12 noviembre, 2019.

Christofoletti, A. (1999). Modelagem de Sistemas Ambientais. São Paulo, Brasil: Edgar Blücher.

Coelho Netto, A. L.; Machado, L. O.; Montezuma, R. de C. M. (2009). “ $O$ Parque Nacional no Maciço da Tijuca: uma unidade de conservação na metrópole do Rio de Janeiro". Unidades de Conservação: abordagens e características geográficas. Rio de Janeiro, Brasil: Bertrand Brasil. (pp. 143-171).

Costa, C. A. da. (2012). Dialética e Interdisciplinaridade: Contribuições ao Debate Ambiental Crítico. Revista Brasileira de Educação Ambiental, v.7, n.2, pp. 77-82.

Drew, D. (1995). Processos Interativos Homem-Meio Ambiente. Rio de Janeiro, Brasil: Bertrand.

Guerra, A. J. T e Marçal, M. S. (2006). Geomorfologia Ambiental. Rio de Janeiro, Brasil: Bertrand do Brasil.

Guerra, A. J. T. e Coelho, M. C. N. - Orgs. (2009). Unidades de Conservação: abordagens e características geográficas. Rio de Janeiro, Brasil: Bertrand Brasil.

IBGE. Censo Demográfico 2010. Disponível em: <http://www.censo2010. ibge.gov.br>. Acesso em: 02 fev. 2019.

Jacobi, P. (1999). Cidade e Meio Ambiente. São Paulo, Brasil: Annablume Editora. 
Leff, E. (2008). Saber Ambiental: Sustentabilidade, racionalidade, complexidade e poder. Petrópolis, RS: Vozes.

Lima, W.P. de. (2015). Parque Natural Municipal de Cabedelo/PB: atividades humanas e impactos ambientais. Monografia de graduação (Bacharelado em Geografia), Departamento de Geociências, Universidade Federal da Paraíba. Brasil (p. 99).

Marques, W. F.; Duarte, M. das D. C.; Medeiros, P. C. R. de. (2008). “ $O$ Parque Natural Municipal de Cabedelo, Estado da Paraíba”. Gestão de áreas protegidas: processos e casos particulares. João Pessoa, Brasil: Ed. Universitária UFPB (pp. 193-197).

Mendonça, F. (1989). Geografia física: ciência humana? São Paulo: Contexto.

Morsello, C. (2008). Áreas protegidas públicas e privadas: seleção e manejo. São Paulo: Annablume, FAPESP.

Moura, J. R. da S.; Costa, V. C. da. (2009). "Parque Estadual da Pedra Branca: o desafio da gestão de uma unidade de conservação em área urbana". Unidades de Conservação: abordagens e características geográficas. Rio de Janeiro: Bertrand Brasil. (pp. 231-265).

Pimentel, A. de A. (2001). Cabedelo. Cabedelo: Prefeitura Municipal de Cabedelo, Secretaria de Educação.

Rocha, S.A. (2006). A valorização da paisagem natural protegida em área urbana: Parque Municipal do Finder, Joinville (SC). Dissertação de mestrado em Geografia), Universidade Federal de Santa Catarina. Brasil (p.107).

Sánchez, L. E. (2013). Avaliação de impacto ambiental: conceitos e métodos. São Paulo: Oficina de Textos.

Santos, M. (2002). A natureza do Espaço: Técnica e Tempo, Razão e Emoção. São Paulo: Edusp.

Souza, N.L. de. (2011). Unidades de Conservação em Áreas Urbanas -o caso do Parque Cinturão Verde de Cianorte - Módulo Mandhuy. RAEGA - O Espaço Geográfico em Análise, v.23, p.448-488.

UICN - União Internacional para a Conservação da Natureza. Disponível em: <https://www.iucn.org/>. Acesso em: 20 mar. 2019. 
